\title{
An Analysis on Environmental Protection in Exploitation of Mineral Resource
}

\author{
Haili Mao \\ School of Chemistry and Chemical Engineering, Qiannan Normal University for Nationalities, Duyun \\ Guizhou, 558000, China
}

Keywords: Mineral resource, Resource exploration, Environmental protection.

\begin{abstract}
Mineral resource is the basic conditions for production and operation of many industries in the social development, and its exploration has become important in the related industry chain. Over the years, the scale of mineral resource exploration has been expanding, and with the continuous development of technology, resource exploration efficiency and quality has been improved, which provides sufficient energy for the social production. At the same time, the ecological and environmental protection issues due to the exploration of mineral resources are growing increasingly. In order to obtain a good living environment, people put forward new requirements for ecological benefits of mineral resource exploration. This paper focuses on the study on environmental protection in exploration of mineral resources, especially from the perspective of their contradiction and unity, relationship status and handling strategy, to hope to share with the majority of experts and scholars.
\end{abstract}

\section{Introduction}

Mineral resource is a concept of a wide range, mainly referring to mineral or elemental geometry geology, including solid, liquid and gaseous and other forms, buried in the underground and formed due to the effect of geological process and mneralizing process. This resource is usually limited, non-renewable, widely distributed, and with different levels of mining difficulty, but all plays a different degree of impetus for the industry production. Therefore, in order to make effective use of natural resources for sustainable development, the exploration of mineral resource has become the focus of resource extraction industry. However, with the progress of science and technology, the economy development and the gradual improvement of people's living standard, environmental problems arising from the exploration of mineral resource are becoming more and more prominent, which does not accord with the survival and life consciousness people continuously enhance and develop. In recent years, discussions and research on mineral resource exploration and environmental protection issues and handling strategies ate gradually white-hot. Therefore, through the access to literature, and combined with relevant experience, the author conducts the further analysis on the brief description, analysis and processing of the relationship between mineral resource exploration and environmental protection, with a view to provide a reference for mineral resource exploration and sustainable social production and development.

\section{Contradiction and unity of exploitation of mineral resource and environmental protection}

The exploitation of mineral resource is already a fixed infrastructure project for each country, and has a vital role for the development of various industries and the basic survival of people. From the development situation of mineral resource projects in China in recent years, the development strategy of "the Belt and Road" provides a broad platform for the further expansion of mineral resource exploitation. According to the relevant information, based on the relevant action plan in 2014, with the development strategy of "the Belt and Road" in the new era aimed to optimize opening pattern, enhance opening level and broaden the field of cooperation, our country has reached a diversified cooperation with countries with rich mineral resource along the Road. In addition, in 2015, "Vision and Action to Promote the Silk Road Economic Zone and the 21st Century Maritime Silk Road" issued by the State Council, clearly takes "to increase exploration and development cooperation of 
coal, oil and gas, metal minerals and other traditional energy resource" as the cooperation priority, and detailed rules further clarify the importance of exploitation of mineral resource in the development strategy in China for some time in the future. It can be seen that the exploitation of mineral resource is conducive and significant for the sustainable development of China's economy and the steady improvement of people's living level. To some extent, the two aspects are unified.

However, with the growing ecological awareness on environmental protection year after year, the exploitation of mineral resource has become one of main factors of environmental pollution. According to the survey data, mineral resource, as the short-term non-renewable natural resource, offers people convenient production and lift, but at the same time, over-exploitation indeed leads to the ecological environment destroyed, and ecological imbalance will eventually cause adverse influences on human development. Specifically, the negative impact of mineral resource exploitation on environmental protection includes the following characteristics. (1) The negative impact of mineral resource exploitation on the natural environment is largely non-timely, and there exists a strong lag effect. First, the environmental carrying capacity of mineral resource exploitation area does not match with the exploitation speed and scale. Second, the mineral resource exploitation process is likely to cause a variety of pollution factors, such as exploitation garbage, mineral accumulation and others, but developers do not deal with the environment issues in a timely manner. Under the condition of the certain dilution and self-cleaning capacity of environment, the larger the scale of exploitation is, the more serious the environment pollution is. We can see that lack of perspectiveness is the primary problem for China's current mineral resource exploitation. (2) Secondly, effects of different types of mineral resource on the environmental pollution and ecological balance in and after the exploitation process are different. Especially in the exploitation of energy and mineral resource, the waste and use of energy is the primary factor for low efficiency of exploitation; at the same time, energy exploitation way is also the important reason for the conflict between exploitation and environmental development. (3) Another important reason for the impact of mineral resource exploitation on the natural environment is the inconformity of industrial structure, exploitation technology and the policy. However, for the current mineral resource exploitation situation, the backwardness of industrial structure and technology and the implementation of the relevant management regulations still seriously hinder the ecological transformation of mineral resource exploitation. Among them, to increase governance force is an important foundation to ensure the ecological environment.

To sum up, at present stage, most of our mineral resource exploitation projects in China have played an important role on related industries to a large extent, but the contradiction between them and the natural ecological environment is still prominent. This requires related departments to conduct a comprehensive intervention from the perspective of technology, strategy and regulatory mode.

\section{An overview of affecting factors of mineral resource exploitation on the environment}

From the above analysis, it can be seen that mineral resource exploitation does have a lagging and large-scale negative impact not able to be ignored on the natural environment and ecological balance. Before dealing with these problems, we should first understand the ecological problems due to mineral resource exploitation. In this regard, through access to literature, and combined with experience, the author summarizes relevant factors of mineral resource exploitation affecting the ecological environment as follows.

(1) Mineral resource exploitation will first have an impact on the original landforms, and even lead to serious geological disasters. We know that mineral resource exploitation is to excavate of the mineral resource below the surface, and usually will change the original landscape of the exploitation area; at the same time, according to the specific needs of the exploitation, facilities construction is required in the mining area, including ore library and the waste-rock yard, and this construction will change the surrounding natural ecological environment. In general, before the exploitation and construction, it is required to investigate and evaluate the landform, geological conditions, climate and landscape conditions and other factors in the exploitation area, and then carry out construction. 
However, in the past years of mineral resource exploitation, many enterprises and departments did not form such a sense of environmental protection, leading to the targeted harm on the original ecological environment, and failed to be dealt with in a timely manner after the exploitation. And once the exploitation causes excessive damage the local cannot withstand, it will easily lead to serious changes in landforms occur, and even landslides, debris flow and other disasters, thus to greater security risks.

(2) Mineral resource exploitation has a negative impact on groundwater and surface water. In general, in the mineral resource exploitation area, below the surface of the mineral resource, there are different reserves of water resource with the specific structure, flow patterns and quality. The process of mineral exploitation usually will directly change the flow direction and flow amount of groundwater, and in the case of over-exploitation, the groundwater recharge will defected, which eventually causes the groundwater depletion. The damage to the groundwater, as the basic conditions for landscape growth, will directly affect the local natural ecological balance. In addition, the exploitation of mineral resource will also cause pollution of groundwater, and some metal minerals will also bring the life and health threat to animals and plants, human beings.

(3) Mineral resource exploitation has an impact on the soil and water elements that maintain vegetation growth. Mineral exploitation is direct excavation to the surface to obtain mineral resources below the surface. However, during the exploitation process, the soil and water conditions in the surface will be changed, including stripping the surface soil of the ore body, destroying landmark plants and the groundwater, the soil structure and the rock structure. At the same time, ore and waste rock after exploitation will destroy the vegetation on the surface, exacerbating soil damage and rock erosion degree in the mining area. And the ore and waste rock is stacked anywhere, which will also cause soil erosion. Too large amount of soil erosion will cause the accumulation of reservoirs and river blockage.

(4) In addition, during mineral exploitation, the dust due to exploitation processes including mine blasting, mineral blasting and processing, is an important cause of air pollution. With the expansion of the scale of exploitation, air pollution will eventually occur, which will increase haze degree and bring a negative impact on people's health.

(5) Mineral exploitation will also have an impact on the lives of nearby residents during its necessary processing phase. First of all, the process of mining, crushing and transportation, especially the blasting process, usually will produce a huge sound, which directly forms noise pollution, and in serious can even will threat people's hearing health and respiratory health.

\section{How to solve the contradiction between mineral resource exploitation and environmental protection}

We have learned that mineral resource exploitation has certain degree of unity and contradictory relationship with natural ecological environment, and at the same time, its impact on natural ecological environment and people's lives are also diverse. It can be seen that to deal with the contradiction between mineral resource exploitation and environmental protection, it is necessary to carry out systematic regulation and optimization from all aspects. In this regard, the author proposes the following suggestions.

(1) Before exploitation, conduct professional, scientific environmental impact assessment on the mine. This requires relevant enterprises and departments to conduct a comprehensive survey on the exploitation environment before mineral resource exploitation, to fully understand the environmental characteristics and then conduct related assessment, including geological topography, hydrology, atmosphere, soil, vegetation and so on. Among them, the assessment dimension can include scientific professionalism, technology, economy and security, ecological balance and so on. Relevant departments should conduct strict supervision and review on the above act.

(2) Properly deal with the waste rock generated during the exploitation process. Among them, at the appropriate location, set the waste rock stacking site, for reasonable and unified stacking of the waste rock during exploitation process. Build retaining embankment below the waste-rock yard for blocking the cement generated when the waste rock yard was washed out. Set drainage ditch above 
the yard, to prevent the external rain into the waste rock yard, in order to reduce the environment pollution due to washout and erosion by the rain. In addition, throughout the production process, based on the emission of rock-soil and waste rock, earth up the rock disposal dumps and planting vegetation in a planned way, thereby improving the ecological environment.

(3) In the exploitation process, plan and control the dust treatment to avoid the formation of air pollution. Specifically, in terms of the timely treatment and long-term treatment, mainly use the spray faucet (for the-timely treatment) and dust removal equipment (for long-term treatment). In addition, in order to protect the comprehensiveness of dust treatment, we can also purchase sprinkler to sprinkle water to ensure that the air quality in the mine lot and avoid pollution spreading.

(4) Conduct professional treatment on the sewage generated during mineral resource exploitation. We know that different types of mineral resource have different nature, and some metal minerals easily bring the threat to the soil, vegetation, water resource and people's life and health. Therefore, we should timely conduct professional treatment on the sewage generated during mineral resource exploitation. For example, during mine water treatment, for its nature of too much acidic substance, use the neutralization strategy with alkaline substances to change the nature of the sewage. Detect different types of sewage and then carry out the classification. In addition, under the condition of resource and economic support, the sewage treatment station can be set up in the appropriate area within the mine area to treat and recycle the sewage.

(5) Conduct necessary greening construction in the mineral resource exploitation area. We know that in many mining areas, mineral exploitation inevitably causes damage to the soil structure and vegetation; therefore, in order to make up for the inherent harm to the environment, it is necessary to establish a corresponding system. We know that greening has a variety of functions, such as wind break and sand fixation, cleaning air, reducing noise and beautifying the environment, therefore, greening in the mining area is also very important. Proper measures should be taken in a number of open locations in the mining area, including land reclamation, planting vegetation, and planting lawn, to a certain extent, to reduce soil erosion in these areas, and avoid landslides, debris flow and other hazards. Especially in mining site, rock disposal dump and tailings ponds, these locations are the key parts in the entire mining area, in which the greening work should be strengthened.

(6) Control noise pollution in the mining area as far as possible. Most of the noise during the exploitation process is from a variety of machinery and equipment, therefore, the most effective way to reduce noise pollution is to take noise-reduction measures on these machines, including shock insulation, sound absorption, or installing noise elimination equipment on the machine, reduce the noise and ensure the nearby residents have a quiet and comfortable living environment.

\section{Conclusions}

In view of the above, mineral resource has a vital role in the development of the country and society. However, in the process of historical exploitation, due to technology, consciousness, economy and policy and other reasons, the management of the mining area is not sufficient, resulting in the impact on the natural environment and ecological balance. For mineral exploitation, part process and necessary products are inevitable. At this time, mining enterprises and relevant departments are necessary to actively intervene to prevent pollution from the source, and even deal with the inevitable pollution in the downstream, so as to minimalize the damage to the natural ecology, and embark on the "green mining" road on which resource exploitation is in harmony with environmental protection.

\section{References}

[1] Chen Jun, Cheng Jinhua. Environmental Impacts of China's Mineral Resource Exploitation and Utilization, Chinese Journal of Resources and Environment, 2015 (03): 111-119.

[2] Tang Jinrong, Zhang Tao, Zhou Ping, et al. Mineral Resource distribution and Investment Environment of "the Belt and the Road", Address Bulletin, 2015 (10): 1918-1928. 
[3] Pan Hongyu. Mineral Exploitation and Land Resource Protection Approach Construction, Finance Sector, 2015 (33): 291.

[4] Zhao Qiulai. Environmental Impacts of China's Mineral Resources Exploitation and Utilization, Heilongjiang Science and Technology Information, 2016 (36): 143.

[5] Yang Shaoliang. Impact of Mineral Resource Exploitation on Environment and Optimization Measures, Chemical Management, 2015 (30): 191. 